\title{
Genomic approaches for understanding dengue: insights from the virus, vector, and host
}

\author{
Shuzhen $\operatorname{Sim}^{1}$ and Martin L. Hibberd ${ }^{1,2^{*}}$
}

\begin{abstract}
The incidence and geographic range of dengue have increased dramatically in recent decades. Climate change, rapid urbanization and increased global travel have facilitated the spread of both efficient mosquito vectors and the four dengue virus serotypes between population centers. At the same time, significant advances in genomics approaches have provided insights into host-pathogen interactions, immunogenetics, and viral evolution in both humans and mosquitoes. Here, we review these advances and the innovative treatment and control strategies that they are inspiring.
\end{abstract}

\section{Background}

Although only nine countries had experienced severe dengue epidemics prior to 1970, the disease is now endemic in more than 100 countries (Fig. 1) [1]. Today, an estimated 3.6 billion people live in areas at risk for epidemic transmission, with nearly 400 million infections occurring annually [2]. This significant public health threat is no longer confined to the tropics - autochthonous dengue transmission has now been recorded in several European countries [3], and in 2014, Japan reported its first outbreak of the disease in 70 years [4].

Dengue virus (DENV) is a positive-sense, singlestranded RNA virus of the family Flaviviridae. The four DENV serotypes (DENV1, 2, 3, and 4) are primarily transmitted between humans by the mosquito Aedes aegypti, with Aedes albopictus as a secondary vector. In many cities, rapid urbanization has resulted in densely packed human and mosquito populations and in an increased

\footnotetext{
* Correspondence: hibberdml@gis.a-star.edu.sg

${ }^{1}$ Infectious Diseases, Genome Institute of Singapore, Singapore 138672, Singapore

${ }^{2}$ Faculty of Infectious and Tropical Diseases, London School of Hygiene and Tropical Medicine, London WC1E 7HT, UK
}

availability of mosquito breeding sites, creating ideal conditions for transmission. At the same time, increased global travel efficiently transports viruses and vectors between population centers [5]. In the future, climate change and consequent increases in temperature and humidity are largely expected to further increase the risk of dengue transmission in both tropical and temperate regions [6-8].

The neglected tropical diseases (NTDs) disproportionately affect the world's poorest populations, and are caused by a diverse array of viral, bacterial, protozoan, and helminthic pathogens. Collectively, they have an approximate global prevalence of $1.0-1.2$ billion cases [ 9 , 10]. Dengue, one of the best-studied NTDs, is among the 17 prioritized by the World Health Organization (WHO) [9]. Funding for dengue research has increased steadily over the past decade, with the vast majority of resources going toward vaccine development [11]. Despite this, an effective tetravalent (eliciting immunity against all four serotypes) vaccine remains elusive [12-15], as does an antiviral that is effective against the virus. Research gaps also exist in the areas of vector control and surveillance.

Technologies that allow us to examine complex hostpathogen interactions from a whole-genome perspective have become more widely available and affordable. This progress is crucial for the development of treatment and control strategies for NTDs, which often suffer from a lack of basic research. This review concentrates on whole-genome studies that have been undertaken on DENV, mosquitoes, and humans to address key research questions. From the virus perspective, we explore studies of inter- and intra-host genetic variation and its effect on viral fitness and transmission. From the host perspective, we review gene-expression-profiling analyses characterizing mosquito and human responses to DENV infection, as well as studies identifying genes that affect susceptibility to virus infection. We further explore the 


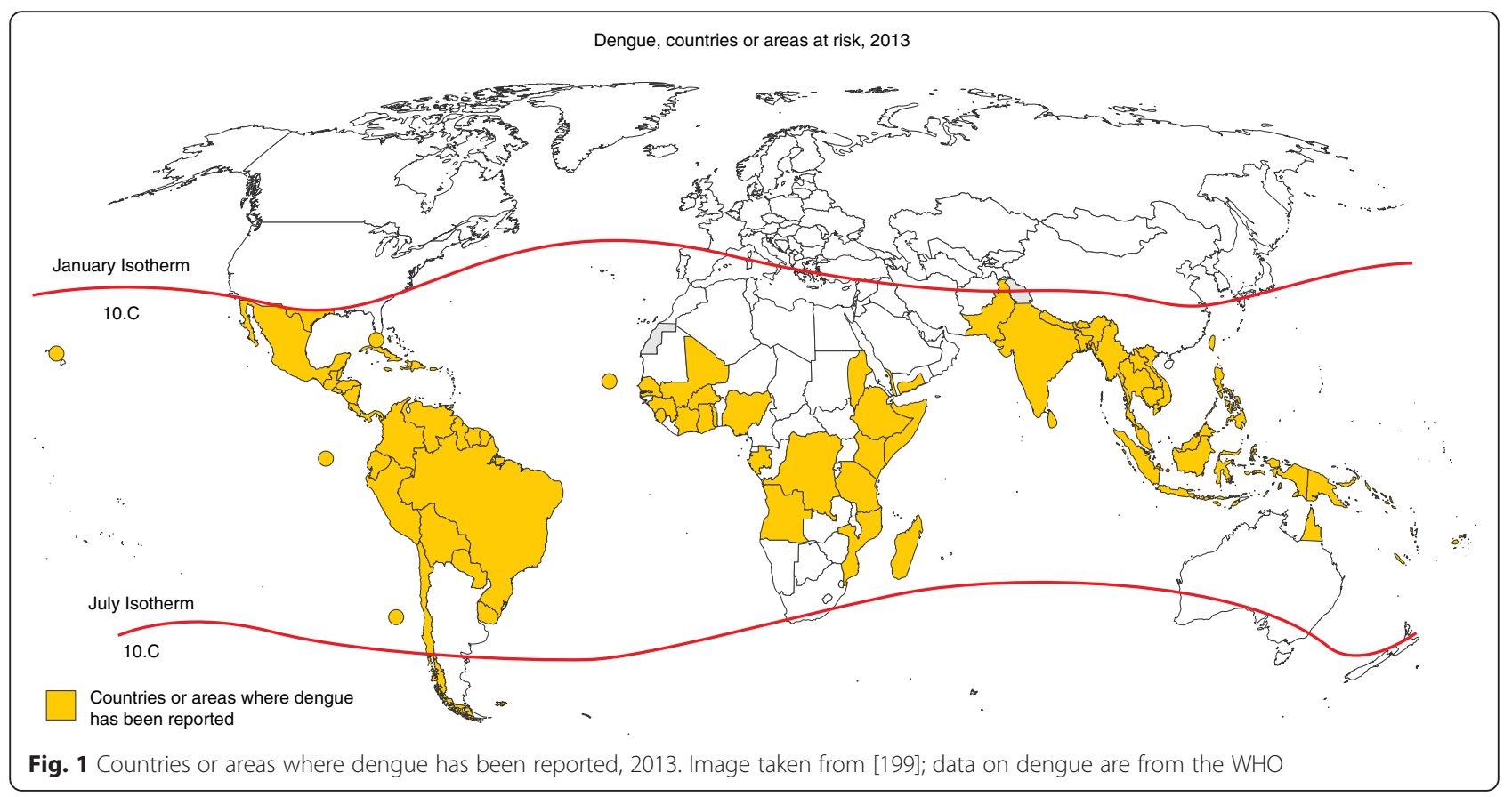

impact of the mosquito midgut microbiota on the virus. Finally, we review the role that genomics studies can play in informing and enabling clinical management, vaccine and drug development, and vector-control strategies.

\section{Virus genetic diversity and its implications for evolution and virulence}

\section{Viral inter-host variation}

In humans, infection with DENV results in a spectrum of clinical outcomes, ranging from self-limiting, uncomplicated dengue fever (DF) to the more severe dengue hemorrhagic fever (DHF), which is characterized by increased vascular permeability and thrombocytopenia (low platelet count). In the most severe cases, these hemorrhagic manifestations lead to potentially fatal hypovolemic shock, a condition known as dengue shock syndrome (DSS). Infection with one serotype of DENV confers short-lived immunity against heterologous serotypes, but after this immunity wanes, heterologous infection carries an increased risk of severe disease. This phenomenon, known as enhancement, may be mediated through antibody responses that are directed against the previous instead of the current serotype, leading to increased viral replication [16] (reviewed in [17]).

The $\sim 10.7 \mathrm{~kb}$ DENV genome encodes three structural proteins (capsid $[\mathrm{C}]$, premembrane $[\mathrm{prM}]$, and envelope $[\mathrm{E}]$ ) and seven non-structural (NS) proteins (NS1, NS2A, NS2B, NS3, NS4A, NS4B, and NS5) (Fig. 2) [18, 19]. Within each of the four DENV serotypes, which share 65-70 \% amino acid sequence similarity [20], virus strains are further classified into distinct genotypes, which can vary by $\sim 6-8 \%$ at the nucleotide level and by $3 \%$ at the amino acid level [21-24]. Amplification and sequencing of DENV directly from patient samples has now become routine in many laboratories, making a large number of DENV sequences available for studies on genetic variation and viral evolution.

Owing to its association with frequent and severe epidemics, DENV2 is the serotype for which the most sequence data are available. Phylogenetic analysis of DENV2 E gene sequences reveals five genotypes, known as the American, Cosmopolitan, Asian, Southeast Asian/ American, and sylvatic genotypes [25-27]. Although these genotypes are largely distinguished by their geographical distributions, they also commonly contain viruses from different locations, an indication of how far infected humans and mosquitoes can spread the virus. This pattern is also true for the other DENV serotypes $[21,28]$, and is likely to become more complex with increased human movement.

Epidemiological data suggest that certain viral genotypes may differ in their ability to cause severe disease (although given suitable conditions, such as enhancing levels of antibody, all serotypes and genotypes have the potential to do so). The introduction of an Asian genotype of DENV2, probably from Vietnam, into Cuba in 1981 and its subsequent spread into the Americas was followed by major outbreaks of DHF [22, 29]; later phylogenetic analyses suggested an association between imported Asian DENV2 genotype sequences and DHF/ DSS [25]. American genotype viruses, by contrast, are not known to cause severe dengue, even in outbreaks 


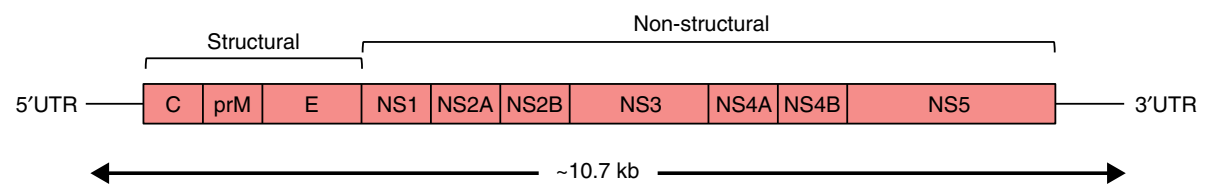

Fig. 2 The dengue virus genome. The $\sim 10.7$ kb DENV genome encodes three structural proteins (capsid [C], premembrane [prM], and envelope $[E]$ ) and seven non-structural (NS) proteins (NS1, NS2A, NS2B, NS3, NS4A, NS4B, and NS5). UTR untranslated region

where secondary infection is common, like that in Peru in the early 1990s [30].

Whole-genome comparisons revealed characteristic differences between DHF/DSS-causing Asian genotype viruses and American genotype viruses [31]. Most notably, differences at amino acid 390 of the E protein and in the $5^{\prime}$ and $3^{\prime}$ untranslated regions (UTRs) affect viral replication in monocyte-derived dendritic cells and in macrophages, with the introduction of the American genotype variant attenuating replication of Asian genotype viruses [32, 33]. Asian genotype viruses also displayed more efficient infection and dissemination in Ae. aegypti mosquitoes $[34,35]$, suggesting that they are also more easily transmitted.

It remains to be seen whether similar distinctions exist within the DENV1 and DENV4 serotypes [36], but certain genotypes of DENV3 have been associated with DHF outbreaks in Tahiti, Fiji, and Sri Lanka (reviewed in $[19,28])$. Functional studies to identify and characterize potential virus determinants of pathogenicity, as described above for DENV2, are lacking.

Some researchers have recently proposed the emergence of a fifth serotype of DENV, based on an atypical virus isolated in 2007 from a patient in Borneo. Reported to be phylogenetically distinct and to elicit an antibody response that differs from that initiated by DENV serotypes $1-4$, this virus is thought to circulate among nonhuman primates, but whether sustained transmission between humans can occur remains unclear [37]. A recent study suggests, however, that there is more antigenic heterogeneity within serotypes than previously thought. By mapping neutralizing antibody responses to a range of DENV1-4 isolates, Katzelnick et al. found that many viruses, while falling within a single serotype on the basis of gene sequence, were as antigenically similar to viruses of other serotypes as they were to each other [38]. This finding has important implications for vaccine development, and claims of 'atypical' virus isolates should also be evaluated with it in mind.

Although we have focused on viral genetics in this section, disease outcomes are in fact influenced by complex interactions between viral and host immunological factors. This was demonstrated in a study carried out in Nicaragua, where an abrupt increase in severe disease has been observed over several years of DENV2 epidemics. OhAinle et al. [39] found that severe disease in later epidemics was associated with waning DENV1 immunity in the population, as well as with replacement of the circulating DENV2 NI-1 virus clade with a new and fitter clade, NI-2B. The contribution of virus clade to increased severity was best explained in the context of serotype-specific immunity - NI-1 viruses were more virulent in children who were immune to DENV1, while $\mathrm{NI}-2 \mathrm{~B}$ viruses were more virulent in DENV3-immune children [39].

\section{Viral intra-host variation in humans}

Like other RNA viruses, DENV has a RNA-dependent RNA polymerase (RdRp, encoded by NS5) that has an intrinsically high error rate $\left(\sim 1 \times 10^{-4}\right.$, corresponding to approximately one mutation per $11 \mathrm{~kb}$ DENV genome) [40]. When coupled with a burst size of $\sim 10^{3}-10^{4}$ genomes per cell $[32,41]$, this error rate results in a population of related but genetically distinct viral genomes, organized around a consensus sequence, within each individual human or mosquito host. Sometimes termed a quasispecies, these variants are thought to interact cooperatively on a functional level, and to contribute collectively to the overall fitness of the virus population, allowing it to adapt to changing environments (reviewed in [40]). High-fidelity poliovirus mutants are markedly attenuated and less able to access the central nervous system in mouse models [42, 43]; high-fidelity mutants of chikungunya virus (a mosquito-borne alphavirus) also show reduced replication and dissemination in both mice and Ae. aegypti [44], demonstrating the importance of genetic diversity during infection. For mosquito-borne viruses, intra-host genetic diversity may also offer an advantage for surviving the distinct selection pressures encountered when cycling between human and mosquito hosts $[44,45]$.

Until recently, studies of DENV intra-host genetic diversity in patient samples involved the Sangersequencing of multiple clones of short regions of one or two viral genes, such as C, E, and NS2B [23, 46-49]. These studies confirmed the presence of measurable intra-host genetic variation in DENV populations, with diversity levels and variant positions differing widely among patients. One study reported lower viral intrahost variation in DHF/DSS than in DF patients, suggesting a relationship between genetic diversity and clinical outcome [47]. Another study found no such association 
between intra-host variation and disease severity, viremia levels, or immune status [23]. These contrasting results may be attributable to a number of variables, including differing immune status and host genetics of patient populations, different circulating virus strains, differences in variant-calling approaches, and statistical noise from low sampling rates. Notably, the latter study, by Thai et al. [23], used a statistically rigorous approach to differentiate true variants from those arising from PCR or sequencing errors, and this probably resulted in their finding levels of diversity that were much lower than those reported previously. Despite this, multiple distinct lineages of the same DENV1 genotype were detected within individual patients, suggesting that mixed infections may be an important contributor to intra-host genetic diversity [23].

High-throughput next-generation sequencing (such as that on the Illumina and 454 platforms) is now being used to study intra-host genetic variation across the entire DENV genome at high coverage (and thus increased sampling rates) [50-53]. This has uncovered varying intra-host diversity levels among both viral genes and different regions of the same gene, indicating that selection pressures vary across the genome. For example, a study of Nicaraguan DENV2 patient samples found that highly immunogenic E-protein domains displayed high levels of intra-host genetic diversity, suggesting that immune selection pressures on viral variants operate even during acute infection [50]. The viruses in this study were classified into two clades, separated by nine amino acid differences, within the same genotype. Intra-host diversity levels were found to be strongly associated with clade identity, suggesting that some amino acid differences may impact diversity, with those in NS5, for example, having the potential to affect polymerase error rates.

\section{Viral intra-host variation in mosquitoes}

In mosquitoes, RNA interference (RNAi), a key antiviral defense mechanism in insects, has been proposed to be a driver of viral intra-host genetic diversity. This has been best studied in the Culex mosquito-West Nile virus (family Flaviviridae) system [54], in which greater intra-host diversity levels were reported in mosquitoes than in vertebrate hosts $[55,56]$. At the same time, host alternation subjects arboviruses to frequent and significant drops in population size. Only a small percentage of the total virus population circulating in the human is ingested by the mosquito host in its $\sim 2 \mu$ l bloodmeal, and an even smaller number of viruses will eventually seed infection in the mosquito gut. Drops in population size also occur during subsequent spread through various tissues and organs of the insect, as well as during the injection of microliter volumes of infected saliva into human hosts. It is unclear how these processes shape the diversity and repertoire of the viral population.

To track changes in viral intra-host genetic diversity during human-to-mosquito transmission, we and collaborators infected Ae. aegypti mosquitoes by allowing them to feed directly on DENV2-infected patients [57]. We then deep-sequenced human- and matched mosquito-derived DENV populations, and used the variant-caller LoFreq [51] to detect true single nucleotide viral variants [58]. Human-, mosquito-abdomen-, and mosquito-salivary-gland-derived DENV populations showed dramatically different variant repertoires: $>90 \%$ of variants were lost at each stage of transmission, most probably due to large population drops that occur during the seeding of infection. Overall levels of viral diversity remained unchanged, however, suggesting that a new array of variants is regenerated by the time of sampling.

The selection pressures imposed on certain viral genes also differed between human and mosquito hosts. Specifically, we observed stronger selection pressures on the prM, E, and NS1 genes in human-derived populations than in mosquito-derived populations, consistent with these gene products being known targets of the human antibody response [59], which has no insect equivalent. By contrast, most variants, even when maintained across transmission stages, appeared to be of neutral fitness value in the mosquito host as their frequencies remained largely unchanged [58].

Viral deep sequencing may also be used to identify potential drug targets. A recent study identified a shared cold-spot, or region with a statistically significant lack of variants, in the NS3 gene of DENV1 populations from human sera and from Ae. aegypti and Ae. albopictus mosquitoes that were intrathoracically inoculated with this sera. The authors suggest that such genetically constrained regions, in which drug-resistant mutations are presumably less likely to arise, can be further explored as antiviral targets. Interestingly, while variants that were common to both mosquito species were observed, there was also evidence of species-specific selection pressures, with two variants in NS5 reproducibly appearing in Ae. aegypti but not in Ae. albopictus [60].

To enable more detailed phylogenetic analyses, molecular biological and statistical methods have been developed to reconstruct full-length viral haplotypes on the basis of short-read sequence data [61, 62]. The continuously increasing length of sequence reads (such as the multikilobase reads now provided by the Pacific Biosciences RS platform) should facilitate such approaches, and also make it possible to obtain viral haplotypes directly from sequence data.

Despite the growing number of studies characterizing DENV intra-host genetic diversity, the impact of this 
diversity on viremia or clinical outcome is not well understood, and studies using rigorous variant-calling algorithms to filter out process errors have found no such associations [23, 50]. However, most studies have sampled virus populations during the acute, viremic phase of the disease; it will be important to determine if disease severity may be associated with the genetic diversity of the infecting viral population, rather than with diversity after the onset of symptoms.

\section{Virus interactions with the mosquito vector Immune responses to DENV}

Once ingested in a bloodmeal taken from an infected human, DENV first infects the midgut epithelium of the mosquito. It subsequently disseminates to other organs via the hemolymph, finally infecting the salivary glands. The virus is secreted into mosquito saliva, and injected into a human host during a subsequent blood-feeding event [5]. Mosquitoes remain infected and able to transmit the virus for life $(\sim 2-3$ weeks in the wild), but DENV does not appear to exert a fitness cost on the vector during natural infection [63].

The mosquito innate immune system can distinguish between broad classes of microbes, and mounts a potent response against viruses, bacteria, and fungi (reviewed in [64]). Whole-genome DNA microarray and RNAsequencing analyses revealed that DENV infection of the mosquito midgut, carcass, and salivary gland transcriptionally regulates numerous genes related to innate immunity, metabolism, and the stress response [65-69]. Among the immunity-related genes, those associated with Toll signaling [65-67], and to a lesser extent Janus kinase/signal transducers and activators of transcription (JAK-STAT) signaling, were prominently represented $[65,68]$. RNAi-mediated gene knockdowns in adult mosquitoes subsequently confirmed key roles for these two pathways in anti-DENV immunity $[65,68]$ : knockdown of Cactus, a negative regulator of the Toll pathway NFkB-like transcription factor Rel1, renders mosquitoes more refractory to DENV infection; whereas knockdown of the adaptor protein MyD88, which is required for Toll signal transduction, increases viral loads in the insect [65]. Similarly, knockdown of protein inhibitor of activated STAT (PIAS), a negative regulator of the JAK-STAT pathway, reduces infection levels, whereas knockdown of the pathway receptor Dome or the JAK ortholog Hop has the opposite effect [68].

The Toll (Rel1)-regulated transcriptome, as determined by expression profiling of Cactus-silenced mosquitoes, comprises almost 2000 genes, consistent with the pathway's diverse roles in immunity and development. Immunity-related signaling molecules and effector genes feature prominently in this dataset, and overlap considerably with those regulated by DENV infection
[65]. The Toll-regulated, DENV-induced antimicrobial peptides (AMPs) cecropin and defensin have been shown by gene knockdown to inhibit DENV proliferation in mosquitoes, possibly through disruption of host cell or viral envelope membranes [66, 70]. Although the Toll pathway has clear antiviral roles, more functional evidence is required to implicate other Toll-regulated genes in anti-DENV defense mechanisms.

By contrast, immunity-related genes comprise only a small proportion of the mosquito's JAK-STAT-regulated transcriptome (as determined through expression profiling of PIAS-silenced mosquitoes), suggesting that this pathway restricts DENV through a non-classical response [68]. Two JAK-STAT-regulated, DENV-induced putative effectors that restrict DENV replication have been identified, but their modes of action remain uncharacterized. Dengue virus restriction factor 1 (DVRF1) is a putative transmembrane protein that presumably functions as a pathway receptor, and DVRF2 contains antifreeze and allergen domains and may be involved in virus recognition [68].

\section{RNAi defense mechanism}

The RNAi mechanism is a key Ae aegypti defense against DENV and other arboviruses [71-73]. The exogenous small interfering RNA (siRNA) response, the best studied of the RNAi pathways, is initiated when long, virus-derived double-stranded RNA (dsRNA) is recognized and cleaved by Dicer-2 (Dcr2) into siRNAs, usually of 21 base pairs (bp) in length. These duplex siRNAs are loaded onto the RNA-induced silencing complex (RISC), which unwinds them, degrading one of the strands and using the other for targeted degradation of single-stranded viral RNA that has a complementary sequence (reviewed in [74]).

Deep sequencing of small RNAs from DENV-infected Ae. aegypti revealed nearly equal ratios of positive- to negative-sense DENV-derived small RNAs, suggesting that most small RNAs are derived from dsRNA replicative intermediates rather than from intra-strand secondary structures [75]. Interestingly, only $0.005-0.06 \%$ of all small RNA reads map specifically to DENV $[75,76]$, a percentage similar to that observed for West Nile virus in Culex mosquitoes [54] but much lower than that for alphaviruses (10\% for Sindbis virus in Ae. aegypti) [77]. It has been proposed that sequestration of flavivirus replication complexes in membrane-enclosed vesicles in mosquito (and mammalian) cells [78], which restricts Dcr2 access to dsRNA replicative intermediates, may account for this. Further, given the low abundance of DENV-derived small RNAs, it has also been suggested that Dcr2 cleavage of dsRNA alone is sufficient to keep viral replication in check [75].

Although 21-bp virus-derived siRNAs dominate during middle- and late-stage infection [75, 76], virus- 
derived small RNAs of 24-30 bp in length are the most prevalent species during early-stage infection [76]. These longer small RNAs are most likely generated by the PIWI RNA (piRNA) pathway, suggesting a role for this Dcr2-independent pathway in anti-DENV defense [76], as has been proposed for other arboviruses $[79,80]$.

\section{Genetic and transcriptomic variation underlying vector competence}

Vector competence - the intrinsic ability of a mosquito to become infected by, support replication of, and transmit a pathogen - varies widely between and within mosquito populations [81-84]. It is genetically determined, but is also influenced by environmental factors (reviewed in [85]). Ae. aegypti vector competence for DENV appears to be an additive trait that is under the control of multiple genetic loci $[86,87]$. Mapping studies have identified several quantitative trait loci (QTLs) that are associated with the ability of DENV to establish infection in the midgut (cross the midgut infection barrier) or to disseminate out of it and infect other tissues (cross the midgut escape barrier) [87-89]. The specific genes or polymorphisms involved, however, have yet to be identified definitively.

In addition, vector competence is influenced by genotype-by-genotype $(\mathrm{GxG})$ interactions, in which infection and dissemination are affected by the specific combination of mosquito and virus genotypes [90, 91]. This complicates genetic mapping because the resistance loci or alleles may differ depending on the mosquito population and the virus strain [92]. For example, natural polymorphisms in Ae. aegypti Dcr2 have been found to be associated with resistance to DENV infection, but in a virus isolate-specific manner. It has been proposed that this specificity is due to differences in the affinity of Dcr2 for particular viral dsRNA sequences [93].

Roughly two-thirds of the $1.4 \mathrm{~Gb}$ Ae. aegypti genome is composed of transposable elements, repeats, or duplications [94, 95], making marker development difficult. Tools are being developed to circumvent these challenges - for example, a recently published singlenucleotide polymorphism (SNP) chip is capable of screening 50,000 SNPs in 96 samples simultaneously [95] - and should facilitate more comprehensive, genome-wide studies of vector competence. Targetedenrichment and deep-sequencing approaches have been developed for the detection of polymorphisms and copy number variations that are associated with insecticide resistance in Ae. aegypti [96]; these approaches could potentially also be adapted to studies of vector competence.

Variation at the transcriptome level is also associated with susceptibility to DENV [84, 97-100]. Microarray expression profiling of the DENV-responsive transcriptomes of refractory and susceptible Ae. aegypti strains revealed differentially expressed gene clusters. These were predominantly related to metabolism and to the stress response, as well as to a common core of DENV-responsive genes, which were mostly related to key signaling pathways, including the JAK-STAT, Wnt, mitogen-activated protein kinase (MAPK), and mammalian target of rapamycin (mTOR) pathways [97-99]. In another study, performed in the absence of DENV infection, expression profiling of a panel of strains from geographically distinct endemic regions found that numerous immunity-related transcripts were more abundant in refractory strains than in susceptible ones, suggesting that basal levels of immune activation impact susceptibility [84]. Given the welldocumented role of gut bacteria in stimulating basal immunity in mosquitoes $[65,101,102]$, it is possible that the co-evolution of these strains with unique suites of microbial species may have resulted in transcriptomic divergence.

Mosquito genes found (using genomic methods) to be associated with vector competence for DENV are listed in Table 1.

\section{Impact of the mosquito microbiome on vector competence}

Mosquitoes harbor bacterial communities that have diverse impacts on nutrition, digestion, metabolism, development, immunity, and other aspects of insect biology $[103,104]$. The adult mosquito gut, in particular, is a site of complex reciprocal interactions between the natural gut microbiota, the mosquito host response, and bloodmeal-acquired pathogens such as DENV. Importantly, the gut microbiome is known to influence vector competence for DENV and other mosquito-borne pathogens (reviewed in [105]).

Removal of native gut bacteria by antibiotic treatment has been reported to render Ae. aegypti more susceptible to DENV infection; these aseptic mosquitoes also display reduced levels of AMP expression [65]. In addition, several bacterial isolates derived from field-collected mosquitoes have the ability to inhibit DENV replication when reintroduced into aseptic mosquito midguts $[102,106]$. In some cases, bacteria are thought to activate basal level production of immune effectors such as AMPs, and thus prime the mosquito against subsequent viral infection $[65$, $70,102]$. This is consistent with known functional overlaps between the mosquito antibacterial and antiviral responses $[65,66,70,102]$. Other bacteria have been shown to inhibit DENV independently of the mosquito, and are thought to produce secondary metabolites that have direct antiviral activity [106].

Bacteria of the genus Wolbachia are maternally inherited, intracellular endosymbionts that naturally infect a wide range of insects, including Drosophila and Ae. albopictus, but not Ae. aegypti. Stable trans-infection of Ae. 
Table 1 Genes associated with susceptibility to DENV in humans and mosquitoes

\begin{tabular}{|c|c|c|c|c|c|}
\hline Host & Gene & Type of variation & Method & Associated with & Reference(s) \\
\hline Human & $M I C B$ & Genetic & GWAS & Severe dengue & [153] \\
\hline Human & PLCE1 & Genetic & GWAS & Severe dengue & [153] \\
\hline Mosquito & Early trypsin & Genetic & QTL analysis & Midgut infection & {$[86,87]$} \\
\hline Mosquito & Dicer-2 & Genetic & Candidate gene sequencing & GXG interactions & [93] \\
\hline Mosquito & Cecropin & Transcriptomic & Microarray/RNAi & Midgut, salivary gland infection & {$[66,70]$} \\
\hline Mosquito & Defensin & Transcriptomic & Microarray/RNAi & Midgut infection & [70] \\
\hline Mosquito & DVRF1 & Transcriptomic & Microarray/RNAi & Midgut infection & {$[68]$} \\
\hline Mosquito & DVRF2 & Transcriptomic & Microarray/RNAi & Midgut infection & {$[68]$} \\
\hline Mosquito & Vacuolar ATPase & Transcriptomic & Microarray/RNAi & Midgut infection & {$[84,189]$} \\
\hline Mosquito & High mobility group box protein (HMGB) & Transcriptomic & Microarray/RNAi & Midgut infection & [84] \\
\hline Mosquito & ML33 & Transcriptomic & Microarray/RNAi & Midgut infection & [186] \\
\hline Mosquito & $\mathrm{NPC1b}$ & Transcriptomic & Microarray/RNAi & Midgut infection & [186] \\
\hline
\end{tabular}

GWAS genome-wide association study, GxG genotype-by-genotype, QTL quantitative trait loci, RNAi RNA interference

aegypti has been achieved through embryo microinjection $[107,108]$, producing mosquitoes that are more resistant to a range of pathogens, including DENV, chikungunya virus (CHIKV), yellow fever virus (YFV), and Plasmodium [109-111]. Microarray analyses indicate that Wolbachia induces the expression of Toll pathway and other immunity-related genes in stably transinfected Ae. aegypti [70, 112, 113]. However, as Wolbachia restricts DENV in Drosophila and Ae. albopictus (two species with a long natural history of Wolbachia infection) in the absence of immune activation, it has been suggested that immune priming is not the fundamental mechanism of virus restriction, although it may enhance the trait in heterologous mosquito hosts [113, 114]. Wolbachia has also been shown to compete with the virus for crucial host resources [115], and to modulate the expression of certain mosquito microRNAs, thereby altering host gene expression to facilitate its own replication $[116,117]$.

In mosquitoes, Wolbachia is particularly suited for use in a population-replacement transmission-blocking strategy because of its ability to induce cytoplasmic incompatibility $(\mathrm{CI})$, a phenomenon (maintained in stably trans-infected Ae. aegypti) in which crosses between uninfected females and infected males result in embryonic lethality (reviewed in [118]). This increases the reproductive success of infected females and allows Wolbachia to spread rapidly through insect populations despite possible fitness costs.

Sequencing-based, culture-independent approaches are increasingly being used to obtain comprehensive profiles of field mosquito microbiomes [119-122]. In Anopheles gambiae, the major African vector of malaria, targeted deep sequencing of microbial 16S ribosomal RNA revealed distinct gut microbiome communities at the aquatic larval and pupal stages and the terrestrial adult stage [119]. This finding is consistent with the fact that gut contents are usually cleared upon metamorphosis during the larvae-to-pupae and pupae-to-adult transitions [123], and implies that repopulation of the microbiome occurs at each stage. Bloodmeals drastically reduced gut microbiome diversity and led to an expansion of members of the Enterobacteriaceae family. These bacteria possess antioxidant mechanisms that may allow them to cope with the oxidative and nitrosative stresses associated with bloodmeal catabolism, suggesting that they benefit the mosquito by helping to maintain gut redox homeostasis [119].

1A study characterizing the microbiomes of wild-caught Aedes, Anopheles, and Culex mosquitoes from Kenya found that the gut microbiome of an individual adult mosquito was typically dominated by one bacterial taxon, while also containing many other much less abundant taxa. Although different mosquito species shared remarkably similar gut bacteria, there was enormous variation within individuals of the same species [120].

The composition and dynamics of endogenous mosquito gut microbiota may affect natural rates of disease transmission, as well as the success of transmissionblocking strategies that involve the introduction of native or non-native bacterial species into mosquito populations. Recent studies, for example, suggest that vertical transmission of Wolbachia in An. gambiae (another non-naturally infected mosquito species) is inhibited by native Asaia $[124,125]$. The development of improved $16 \mathrm{~S}$ sequencing methods that allow species-level identification [126], as well as metagenomic sequencing approaches that yield information on microbial function in addition to identity [127, 128], should help us understand complex relationships between bacterial communities and their insect hosts. 


\section{Virus interactions with the human host Transcriptome profiling of the human host}

DENV probably infects a wide range of cell types in the human host. Mouse studies suggest that hepatocytes are perhaps the most important cells for replication [129], but most human studies have concentrated on monocytes, macrophages, and dendritic cells [130, 131]. Acute disease, occurring 3-8 days after viral transmission from the mosquito, typically begins with a 3-7-day febrile phase, accompanied by symptoms such as headache, myalgia, arthralgia, retro-orbital pain, and rash. While most patients subsequently recover without complications, some progress to severe disease at around the time of defervescence (abatement of fever; reviewed in [132]).

Longitudinal studies using DNA microarray expression profiling to track transcriptomic changes in the blood of DENV-infected patients have identified two distinct phases of gene expression during the febrile stage. In the early acute phase (day $0-1$, day 0 being the day of fever onset), genes associated with innate immunity, interferon (IFN)- and cytokine-mediated signaling, chemotaxis, and complement pathway activity reach peak expression but their expression declines by day $3-4$, mirroring viremia levels. This marks a shift to the late acute phase, which is characterized by the expression of genes associated with the cell cycle and DNA repair, which peaks at day 5-6 [133, 134].

These results are consistent with cross-sectional studies that have identified IFN, NF-kB, Toll-like receptor (TLR), retinoic acid-inducible gene-I-like receptor (RLR), complement, and ubiquitin-proteasome pathway-related genes as prominent features of the febrile-stage transcriptional signature [135-140]. A number of these host responses look to have either pro-inflammatory profiles that may lead to later disease pathology or antiviral activities (or both) [137, 141], and may represent promising novel drug targets. The first clinical trial of a therapy exploiting a host target to inhibit viral replication did not, however, show sufficient activity [142]. The antiviral innate immune response profile wanes rapidly, and by the defervescent stage, transcripts of genes that are involved in biosynthesis, metabolism, and the adaptive immune response are most prominent $[135,136,139,140]$; these may be less easily used as therapeutic targets.

Hemorrhagic manifestations leading to DSS typically appear around defervescence (day 4-7 of illness), when the host immune response is well established and viremia is rapidly declining. This suggests that vascular permeability is mediated by the host inflammatory response rather than by the virus directly. The onset of shock appears to be associated with an attenuated immune response, with several studies reporting reduced transcript abundances of IFN-stimulated and other innate immunity-related genes in DSS compared with those in well-matched DF patients prior to [143, 144] and at the point of defervescence $[135,139]$. Thus, the host responses that contribute to vascular permeability may occur well before the onset of DSS, with rapid early disease progression being an important determinant of severe outcome, probably reflecting an earlier and larger peak viral load and a consequent earlier and larger host response [135].

Prospective studies designed to capture these early events found that dengue patients who eventually progress to DHF/DSS display an early increased abundance of transcripts associated with activated neutrophils, including those encoding granulocyte enzymes, membrane-bound integrin receptors, and microbicidal peptides such as defensins $[136,145,146]$. Several of these proteins might compromise capillary integrity - the serine proteases ELA2 and CTSG, for example, are known to cleave vascular endothelial cadherin [147]. It has thus been proposed that high viral antigen loads and immune complex formation (as seen in secondary dengue) during early infection induce neutrophil activation and degranulation, which then contribute to the triggering of vascular permeability [136]. Intriguingly, the platelet drop observed in patients and associated with disease severity may not be linked with these vascular permeability changes, but may instead be an independent event resulting from the inhibition of platelet production by the early inflammatory response [129]. (While most studies cited here classified patients as having DF, DHF, or DSS, we note that the WHO in 2009 revised its guidelines so that patients are now classified as having 'dengue with or without warning signs' or 'severe dengue' [148].)

While a detailed discussion is outside the scope of this review, techniques such as mass spectrometry and immunoassays have also been used to study human host responses to DENV infection and to distinguish mild from severe dengue disease at the proteome level [149-152].

\section{Genetic associations}

In addition to expression profiling, genome-wide association studies (GWAS) have also contributed to our understanding of the pathogenesis of severe dengue. Strong associations with increased susceptibility to DSS have been identified at two distinct loci: MICB (MHC class I polypeptide-related sequence $B$ ), located within the major histocompatibility complex (MHC) region on chromosome 6; and PLCE1 (Phospholipase C, epsilon 1), located on chromosome 10 (Table 1) [153].

$M I C B$ encodes an inducible activating ligand for the NKG2D type II receptor on natural killer (NK) cells and CD8+ $\mathrm{T}$ cells. Binding of MICB to NKG2D activates antiviral functions such as cytotoxic granule release and cytokine production [154]; it is possible that dysfunctional $\mathrm{NK}$ or $\mathrm{CD} 8+\mathrm{T}$-cell activation during early 
infection results in the higher viral burdens associated with severe dengue $[155,156]$. Interestingly, a separate GWAS detected an association between the closely related MICA gene and hepatitis $\mathrm{C}$ virus ( $\mathrm{HCV}$ )-induced hepatocellular carcinoma [152], suggesting an important role for the MIC proteins in flaviviral pathogenesis.

Mutations in PLCE1 are also associated with nephrotic syndrome [157, 158], a childhood kidney disorder in which dysfunction of the glomerular basement membrane impairs blood filtering function, leading to hypovolemia in severe cases. This aspect of nephrotic syndrome shares striking similarities with DSS, and has led to the discovery that proteinuria may be predictive of severe dengue [159]. PLCE1 has also been associated with blood pressure [160], suggesting a role in the maintenance of normal vascular endothelial barrier function. Disturbances in this vascular integrity may be the cause of DSS, offering the potential for a novel therapeutic approach to prevent it. This process may also go some way to explaining the association of DSS with pediatric dengue, as children are intrinsically more prone to vascular leak [161].

\section{Implications and future challenges for clinical management and transmission control \\ Clinical management of dengue}

Dengue is a significant burden on healthcare systems. Without specific antivirals, the case management of high-risk dengue patients is entirely supportive, involving constant monitoring and timely fluid support to prevent hypovolemic shock [132]. Nevertheless, the diverse clinical spectrum of dengue disease, as well as its initial similarity to other viral febrile illnesses, presents a challenge in the early identification of this relatively small high-risk group (perhaps $5 \%$ of cases), resulting in the frequent hospitalization of patients with uncomplicated dengue or the non-hospitalization of patients who would benefit from interventions. WHO guidelines [148] recommend the use of warning signs to identify high-risk patients, but these have potential to be overly sensitive [162-164] and they generally occur during, or just one day before, the development of severe illness (4-7 days post-fever onset), providing only a narrow window for clinical intervention $[164,165]$.

Transcriptomic profiling of patients at early time points has greatly increased our understanding of dengue pathogenesis, and has identified host-response biomarkers that are associated with subsequent development of warning signs and progression to severe disease [133, 134, 136, 140, 144, 166]. Prognostic models combining mRNA and protein biomarkers with clinical parameters (such as platelet count) have also been developed and tested in proof-of-concept studies [133, 166, 167]. These have potential to further refine clinical triage, and would be particularly useful in primary healthcare settings; evaluation in larger prospective studies is needed for them to be applied more widely.

\section{Vaccine and drug development}

There remains a pressing need for effective vaccines and specific antivirals against dengue. The approval in December 2015 of Sanofi-Pasteur's tetravalent vaccine Dengvaxia (CYD-TDV) for use in Mexico in a select age group (9-45 years) is certainly an achievement, but is unlikely to be a single solution. Although CYD-TDV is well tolerated in the short term and substantially reduces dengue hospitalizations, it shows serotype-specific efficacy, with less protection against serotype 2 , and also provides limited protection against primary infection $[14,15]$. Third-year follow-up data also indicate that CYD-TDV is associated with increased hospitalization risk for dengue in children below 9 years of age, raising the possibility that waning antibody titers predispose this age group to infection and more serious clinical presentations [12, 13], and highlighting the need for vaccines to elicit potent and balanced antibody responses even in dengue-naive recipients. On the therapeutics front, the candidate antivirals celgosivir (a host $\alpha$-glucosidase inhibitor) and balapiravir (a nucleoside analog) were not found to be effective in clinical trials, despite promising activity in in vitro and animal models [142, 168]. This failure may be due to the very small window of therapeutic opportunity for antivirals, suggesting that prophylactic approaches might be required. In addition, antiinflammatory approaches using re-purposed therapies have also proven to be ineffective to date [169, 170], although this might be due to their targeting of inappropriate host responses [171].

Efforts to develop improved next-generation vaccine and antiviral candidates will benefit from structural and functional genomics studies in both virus and host [172-174], which may identify regions of the viral genome [51, 58,60] or novel host-viral interactions $[141,175]$ as potential targets.

Viral sequencing may be used to evaluate the effect of antivirals and vaccines on DENV populations, and to monitor the emergence of resistant or immune escape mutants. For example, although balapiravir induces $\mathrm{C}>\mathrm{N}$ mutations by inhibiting the incorporation of cytosine bases into RNA templates by viral NS5 [176], deep sequencing revealed no differences in the frequency of these mutations between viral populations from drug- and placebo-treated patient groups [51]. This may provide a molecular explanation for its lack of efficacy in clinical trials [168].

In another study, DENV populations from mice treated with UV-4B, a host $\alpha$-glucosidase inhibitor [177] soon to enter clinical trials, harbored significantly more 
variants than those from vehicle-treated mice. They also showed high ratios of non-synonymous to synonymous variants in the glycosylated M and NS1 proteins, suggesting that the drug is driving positive selection in these regions of the genome. Despite this, no escape mutants emerged even after multiple rounds of virus replication; the authors suggest that this reflects the better stability of antiviral approaches that target host factors [52].

\section{Control strategies targeting the mosquito vector}

Novel control strategies targeting the mosquito vector are being tested in natural settings. Field releases of $A e$. aegypti carrying the wMel strain of Wolbachia successfully introduced the bacterium into Australian mosquito populations, where it has remained established to date [111, 178]. Ongoing releases in Vietnam, Indonesia, Brazil, and Colombia [179], where dengue is much more common than in Australia, should yield information on the impact of population replacement on disease transmission.

Strategies involving genetically modified mosquitoes are also under development. The most advanced of these, termed release of insects carrying a dominant lethal allele (RIDL), seeks to eliminate vector populations by releasing males carrying a transgene that renders their offspring non-viable. One such construct induces cellular toxicity specifically in the flight muscles of female pupae, resulting in adult females that are unable to fly [180]; another induces lethality at the late larval or pupal stage [181]. Trials of RIDL mosquito strains have been carried out in the Cayman Islands, Brazil, and Malaysia by the company Oxitec, with a $95 \%$ population reduction reported at the Brazilian field site [182-185].

Mosquito transcriptomics studies have yielded a plethora of DENV-responsive genes; these are increasingly being functionally characterized, and some have been found to play pro- or antiviral roles in the vector [186-189]. Such studies can identify candidate molecules for use in experimental transmission-blocking strategies, such as the transgenic overexpression of immune pathway activators or antiviral effectors [190-192], and the paratransgenic engineering of bacterial or fungal members of the microbiome to express anti-pathogen molecules [193-195]. Recent reports of Anopheles species engineered with the CRISPR-Cas9 gene drive system so that they are refractory to Plasmodium infection [196, 197] suggest that population replacement strategies are technically feasible, but should be adopted with caution [198].

In practice, control strategies targeting the vector will probably be complicated by genetic and transcriptomic divergence in mosquito and virus strains, and by the influence of the native gut microbiota. A combination of functional genomics and extensive field testing will most probably be required to overcome these challenges.

\section{Conclusion}

In microbiology, there is increasing appreciation that host genetics, host gene expression, host immune background, and pathogen genetics are interrelated and should not be studied in isolation. The impact of DENV on the human host, in terms of clinical phenotype and host response, is shaped by host genetics, prior immune exposure, and virus genetics; in mosquitoes (and possibly even in humans), the gut microbiota adds an additional layer of complexity. Reciprocally, immune selection pressures exerted by either host shape the genetic diversity of DENV populations, potentially impacting their virulence, immunogenicity, or transmissibility.

Genomics approaches have allowed us to interrogate host-pathogen interactions on an unprecedented scale. This provides opportunities for integrating information from different taxa to attain a comprehensive picture of DENV in human and mosquito hosts. For example, with more whole-genome virus sequences becoming available, it will be possible to correlate DENV polymorphisms with host genotypes and clinical phenotypes, with specific immune pressures such as antiviral use, or with different subsets of mosquito gut bacteria. Continued dissection of such interactions to reveal their molecular mechanisms will provide new and better targets for the development of vaccines and antivirals, as well as for transmission-blocking strategies targeting the vector.

\section{Abbreviations \\ AMP: Antimicrobial peptide; C: Capsid; Dcr2: Dicer-2; DENV: Denque virus; DF: Dengue fever; DHF: Dengue hemorrhagic fever; dsRNA: Double-stranded RNA; DSS: Denque shock syndrome; DVRF1: Denque virus restriction factor 1; E: Envelope; GWAS: Genome-wide association studies; IFN: Interferon; JAK-STAT: Janus kinase/signal transducers and activators of transcription; MHC: Major histocompatibility complex; MICB: MHC class I polypeptide-related sequence B; NK: Natural killer; NS: Non-structural; NTD: Neglected tropical disease; PIAS: Protein inhibitor of activated STAT; PLCE1: Phospholipase C, epsilon 1; prM: Premembrane; RNAi: RNA interference; siRNA: Small interfering RNA; SNP: Single-nucleotide polymorphism; WHO: World Health Organization.}

Competing interests

The authors declare that they have no competing interests.

Authors' contributions

Both authors read and approved the final manuscript.

Published online: 02 March 2016

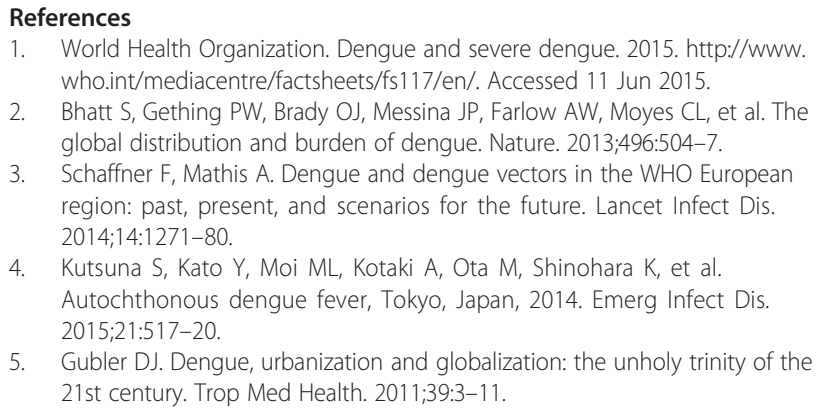

1. World Health Organization. Dengue and severe dengue. 2015. http://www. who.int/mediacentre/factsheets/fs117/en/. Accessed 11 Jun 2015.

2. Bhatt $S$, Gething PW, Brady OJ, Messina JP, Farlow AW, Moyes $C L$, et al. The global distribution and burden of dengue. Nature. 2013;496:504-7.

3. Schaffner F, Mathis A. Dengue and dengue vectors in the WHO European region: past, present, and scenarios for the future. Lancet Infect Dis. 2014;14:1271-80.

4. Kutsuna S, Kato Y, Moi ML, Kotaki A, Ota M, Shinohara K, et al. Autochthonous dengue fever, Tokyo, Japan, 2014. Emerg Infect Dis. 2015;21:517-20

5. Gubler DJ. Dengue, urbanization and globalization: the unholy trinity of the 21st century. Trop Med Health. 2011;39:3-11. 
6. Bouzid M, Colón-González FJ, Lung T, Lake IR, Hunter PR. Climate change and the emergence of vector-borne diseases in Europe: case study of dengue fever. BMC Public Health. 2014;14:781.

7. Colón-González FJ, Fezzi C, Lake IR, Hunter PR. The effects of weather and climate change on dengue. PLoS Negl Trop Dis. 2013;7:e2503.

8. Naish S, Dale P, Mackenzie JS, McBride J, Mengersen K, Tong S. Climate change and dengue: a critical and systematic review of quantitative modelling approaches. BMC Infect Dis. 2014;14:167.

9. World Health Organization. Neglected tropical diseases. http://www.who.int/ neglected_diseases/diseases/en/. Accessed 21 Aug 2015.

10. Hotez PJ, Fenwick A, Savioli L, Molyneux DH. Rescuing the bottom billion through control of neglected tropical diseases. Lancet. 2009:373:1570-5.

11. Horstick O, Tozan Y, Wilder-Smith A. Reviewing dengue: still a neglected tropical disease? PLoS Negl Trop Dis. 2015;9:e0003632.

12. Hadinegoro SR, Arredondo-García JL, Capeding MR, Deseda C, Chotpitayasunondh $T$, Dietze $R$, et al. Efficacy and long-term safety of a dengue vaccine in regions of endemic disease. N Engl J Med. 2015;373:1195-206.

13. Simmons CP. A candidate dengue vaccine walks a tightrope. N Engl J Med. 2015;373:1263-4

14. Sabchareon A, Wallace $D$, Sirivichayakul $C$, Limkittikul $K$, Chanthavanich $P$, Suvannadabba $\mathrm{S}$, et al. Protective efficacy of the recombinant, liveattenuated, CYD tetravalent dengue vaccine in Thai schoolchildren: a randomised, controlled phase 2b trial. Lancet. 2012;380:1559-67.

15. Capeding MR, Tran NH, Hadinegoro SRS, Ismail HIHM, Chotpitayasunondh T, Chua MN, et al. Clinical efficacy and safety of a novel tetravalent dengue vaccine in healthy children in Asia: a phase 3, randomised, observer-masked, placebo-controlled trial. Lancet. 2014;384:1358-65.

16. Chan KR, Ong EZ, Tan HC, Zhang SL-X, Zhang Q, Tang KF, et al. Leukocyte immunoglobulin-like receptor B1 is critical for antibody-dependent dengue. Proc Natl Acad Sci U S A. 2014;111:2722-7.

17. Rothman AL. Immunity to dengue virus: a tale of original antigenic sin and tropical cytokine storms. Nat Rev Immunol. 2011;11:532-43.

18. Whitehead SS, Blaney JE, Durbin AP, Murphy BR. Prospects for a dengue virus vaccine. Nat Rev Microbiol. 2007:5:518-28.

19. Clyde K, Kyle JL, Harris E. Recent advances in deciphering viral and host determinants of dengue virus replication and pathogenesis. J Virol. 2006;80:11418-31.

20. Guzman MG, Halstead SB, Artsob H, Buchy P, Farrar J, Gubler DJ, et al. Dengue: a continuing global threat. Nat Rev Microbiol. 2010;8:S7-16.

21. Holmes EC, Twiddy SS. The origin, emergence and evolutionary genetics of dengue virus. Infect Genet Evol. 2003;3:19-28.

22. Rico-Hesse R. Molecular evolution and distribution of dengue viruses type 1 and 2 in nature. Virology. 1990;174:479-93.

23. Thai KTD, Henn MR, Zody MC, Tricou V, Nguyet NM, Charlebois P, et al. High-resolution analysis of intrahost genetic diversity in dengue virus serotype 1 infection identifies mixed infections. J Virol. 2012;86:835-43.

24. Ty Hang VT, Holmes EC, Veasna D, Quy NT, Tinh Hien T, Quail M, et al. Emergence of the Asian 1 genotype of dengue virus serotype 2 in Viet Nam: in vivo fitness advantage and lineage replacement in South-East Asia. PLoS Negl Trop Dis. 2010;4:e757.

25. Rico-Hesse R, Harrison LM, Salas RA, Tovar D, Nisalak A, Ramos C, et al. Origins of dengue type 2 viruses associated with increased pathogenicity in the Americas. Virology. 1997;230:244-51.

26. Twiddy SS, Farrar JJ, Vinh Chau N, Wills B, Gould EA, Gritsun T, et al. Phylogenetic relationships and differential selection pressures among genotypes of dengue-2 virus. Virology. 2002;298:63-72.

27. Vasilakis N, Fokam EB, Hanson CT, Weinberg E, Sall AA, Whitehead SS, et al. Genetic and phenotypic characterization of sylvatic dengue virus type 2 strains. Virology. 2008;377:296-307.

28. Rico-Hesse R. Microevolution and virulence of dengue viruses. Adv Virus Res. 2003;59:315-41.

29. Gubler DJ. Dengue and dengue hemorrhagic fever. Clin Microbiol Rev. 1998;11:480-96.

30. Watts DM, Porter KR, Putvatana P, Vasquez B, Calampa C, Hayes CG, et al. Failure of secondary infection with American genotype dengue 2 to cause dengue haemorrhagic fever. Lancet. 1999;354:1431-4.

31. Leitmeyer KC, Vaughn DW, Watts DM, Salas R, Villalobos I, de Chacon, et al. Dengue virus structural differences that correlate with pathogenesis. J Virol. 1999;73:4738-47.

32. Cologna R, Rico-Hesse R. American genotype structures decrease dengue virus output from human monocytes and dendritic cells. $J$ Virol. 2003;77:3929-38.
33. Pryor MJ, Carr JM, Hocking H, Davidson AD, Li P, Wright PJ. Replication of dengue virus type 2 in human monocyte-derived macrophages: comparisons of isolates and recombinant viruses with substitutions at amino acid 390 in the envelope glycoprotein. Am J Trop Med Hyg. 2001;65:427-34.

34. Armstrong PM, Rico-Hesse R. Efficiency of dengue serotype 2 virus strains to infect and disseminate in Aedes aegypti. Am J Trop Med Hyg. 2003;68:539-44

35. Anderson JR, Rico-Hesse R. Aedes aegypti vectorial capacity is determined by the infecting genotype of dengue virus. Am J Trop Med Hyg. 2006;75:886-92.

36. Rico-Hesse R. Dengue virus virulence and transmission determinants. Curr Top Microbiol Immunol. 2010;338:45-55.

37. Normile D. Surprising new dengue virus throws a spanner in disease control efforts. Science. 2013;342:415.

38. Katzelnick LC, Fonville JM, Gromowski GD, Arriaga JB, Green A, James SL, et al. Dengue viruses cluster antigenically but not as discrete serotypes. Science. 2015:349:1338-43.

39. OhAinle M, Balmaseda A, Macalalad AR, Tellez Y, Zody MC, Saborío S, et al. Dynamics of dengue disease severity determined by the interplay between viral genetics and serotype-specific immunity. Sci Transl Med. 2011:3:114ra128.

40. Lauring AS, Andino R. Quasispecies theory and the behavior of RNA viruses. PLoS Pathog. 2010;6:e1001005.

41. Wang W-K, Sung T-L, Tsai Y-C, Kao C-L, Chang S-M, King C-C. Detection of dengue virus replication in peripheral blood mononuclear cells from dengue virus type 2 -infected patients by a reverse transcription-real-time PCR assay. J Clin Microbiol. 2002:40:4472-8.

42. Vignuzzi $M$, Wendt $E$, Andino R. Engineering attenuated virus vaccines by controlling replication fidelity. Nat Med. 2008;14:154-61.

43. Vignuzzi M, Stone JK, Arnold JJ, Cameron CE, Andino R. Quasispecies diversity determines pathogenesis through cooperative interactions in a viral population. Nature. 2006:439:344-8.

44. Coffey LL, Beeharry Y, Bordería AV, Blanc H, Vignuzzi M. Arbovirus high fidelity variant loses fitness in mosquitoes and mice. Proc Natl Acad Sci U S A. 2011;108:16038-43.

45. Coffey LL, Vignuzzi M. Host alternation of Chikungunya virus increases fitness while restricting population diversity and adaptability to novel selective pressures. J Virol. 2011:85:1025-35.

46. Lin S-R, Hsieh S-C, Yueh Y-Y, Lin T-H, Chao D-Y, Chen W-J, et al. Study of sequence variation of dengue type 3 virus in naturally infected mosquitoes and human hosts: implications for transmission and evolution. J Virol. 2004;78:12717-21.

47. Descloux E, Cao-Lormeau V-M, Roche C, De Lamballerie X. Dengue 1 diversity and microevolution, French Polynesia 2001-2006: Connection with epidemiology and clinics. PLoS Negl Trop Dis. 2009;3:e493.

48. Wang W-K, Lin S-R, Lee C-M, King C-C, Chang S-C. Dengue type 3 virus in plasma is a population of closely related genomes: quasispecies. J Virol. 2002; 76:4662-5.

49. Wang $W-K$, Sung T-L, Lee C-N, Lin T-Y, King C-C. Sequence diversity of the capsid gene and the nonstructural gene NS2B of dengue-3 virus in vivo. Virology. 2002;303:181-91.

50. Parameswaran $\mathrm{P}$, Charlebois $\mathrm{P}$, Tellez $\mathrm{Y}$, Nunez A, Ryan EM, Malboeuf $\mathrm{CM}$, et al. Genome-wide patterns of intrahuman denque virus diversity reveal associations with viral phylogenetic clade and interhost diversity. J Virol. 2012:86:8546-58.

51. Wilm A, Aw PPK, Bertrand D, Yeo GHT, Ong SH, Wong CH, et al. LoFreq: a sequence-quality aware, ultra-sensitive variant caller for uncovering cell-population heterogeneity from high-throughput sequencing datasets. Nucleic Acids Res. 2012:40:11189-201.

52. Plummer E, Buck MD, Sanchez M, Greenbaum JA, Turner J, Grewal R, et al. Dengue virus evolution under a host-targeted antiviral. J Virol. 2015;89:5592-601.

53. Romano CM, Lauck M, Salvador FS, Lima CR, Villas-Boas LS, Araújo ESA, et al. Inter- and intra-host viral diversity in a large seasonal DENV2 outbreak. PLoS One. 2013;8:e70318.

54. Brackney DE, Beane JE, Ebel GD. RNAi targeting of West Nile virus in mosquito midguts promotes virus diversification. PLoS Pathog. 2009:5:e1000502.

55. Jerzak G, Bernard KA, Kramer LD, Ebel GD. Genetic variation in West Nile virus from naturally infected mosquitoes and birds suggests quasispecies structure and strong purifying selection. J Gen Virol. 2005;86:2175-83. 
56. Jerzak GVS, Bernard K, Kramer LD, Shi P, Ebel GD. The West Nile virus mutant spectrum is host-dependant and a determinant of mortality in mice. Virology. 2007;360:469-76.

57. Nguyen NM, Kien DTH, Tuan TV, Quyen NTH, Tran CNB, Thi LV, et al. Host and viral features of human dengue cases shape the population of infected and infectious Aedes aegypti mosquitoes. Proc Natl Acad Sci U S A. 2013;110:9072-7.

58. Sim S, Aw PPK, Wilm A, Teoh G, Hue KDT, Nguyen NM, et al. Tracking dengue virus intra-host genetic diversity during human-to-mosquito transmission. PLoS Negl Trop Dis. 2015;9:e0004052.

59. Wahala WMPB, de Silva AM. The human antibody response to dengue virus infection. Viruses. 2011;3:2374-95.

60. Sessions OM, Wilm A, Kamaraj US, Choy MM, Chow A, Chong Y, et al. Analysis of dengue virus genetic diversity during human and mosquito infection reveals genetic constraints. PLoS Negl Trop Dis. 2015;9:e0004044.

61. Kortenhoeven $C$, Joubert F, Bastos AD, Abolnik C. Virus genome dynamics under different propagation pressures: reconstruction of whole genome haplotypes of West Nile viruses from NGS data. BMC Genomics. 2015;16:118.

62. Hong LZ, Hong S, Wong HT, Aw PP, Yan C, Wilm A, et al. BAsE-Seq: a method for obtaining long viral haplotypes from short sequence reads. Genome Biol. 2014;15:517.

63. Carrington LB, Nguyen HL, Nguyen NM, Duong THK, Tuan TV, Giang NT, et al. Naturally-acquired dengue virus infections do not reduce short-term survival of infected Aedes aegypti from Ho Chi Minh City, Vietnam. Am J Trop Med Hyg. 2015;92:492-6.

64. Sim S, Jupatanakul N, Dimopoulos G. Mosquito immunity against Arboviruses. Viruses. 2014;6:4479-504.

65. Xi Z, Ramirez JL, Dimopoulos G. The Aedes aegypti Toll pathway controls dengue virus infection. PLoS Pathog. 2008:4:e1000098.

66. Luplertlop N, Surasombatpattana P, Patramool S, Dumas E, Wasinpiyamongkol L, Saune L, et al. Induction of a peptide with activity against a broad spectrum of pathogens in the Aedes aegypti salivary gland, following infection with dengue virus. PLoS Pathog. 2011;7:e1001252.

67. $\operatorname{Sim}$ S, Ramirez JL, Dimopoulos G. Dengue virus infection of the Aedes aegypti salivary gland and chemosensory apparatus induces genes that modulate infection and blood-feeding behavior. PLoS Pathog. 2012;8:e1002631.

68. Souza-Neto JA, Sim S, Dimopoulos G. An evolutionary conserved function of the JAK-STAT pathway in anti-dengue defense. Proc Natl Acad Sci U S A. 2009;106:17841-6.

69. Bonizzoni M, Dunn WA, Campbell CL, Olson KE, Marinotti O, James AA. Complex modulation of the Aedes aegypti transcriptome in response to dengue virus infection. PLoS One. 2012;7:e50512.

70. Pan X, Zhou G, Wu J, Bian G, Lu P, Raikhel AS, et al. Wolbachia induces reactive oxygen species (ROS)-dependent activation of the Toll pathway to control dengue virus in the mosquito Aedes aegypti. Proc Natl Acad Sci U S A. 2012;109:E23-31.

71. McFarlane M, Arias-Goeta C, Martin E, O'Hara Z, Lulla A, Mousson L, et al. Characterization of Aedes aegypti innate-immune pathways that limit Chikungunya virus replication. PLoS Negl Trop Dis. 2014;8:e2994.

72. Campbell CL, Keene KM, Brackney DE, Olson KE, Blair CD, Wilusz J, et al. Aedes aegypti uses RNA interference in defense against Sindbis virus infection. BMC Microbiol. 2008:8:47.

73. Sánchez-Vargas I, Scott JC, Poole-Smith BK, Franz AWE, Barbosa-Solomieu V, Wilusz J, et al. Dengue virus type 2 infections of Aedes aegypti are modulated by the mosquito's RNA interference pathway. PLoS Pathog. 2009;5:e1000299.

74. Sanchez-Vargas I, Travanty EA, Keene KM, Franz AW, Beaty BJ, Blair CD, et al. RNA interference, arthropod-borne viruses, and mosquitoes. Virus Res. 2004;102:65-74.

75. Scott JC, Brackney DE, Campbell CL, Bondu-Hawkins V, Hjelle B, Ebel GD, et al. Comparison of dengue virus type 2-specific small RNAs from RNA interference-competent and -incompetent mosquito cells. PLoS Negl Trop Dis. 2010;4:e848

76. Hess AM, Prasad AN, Ptitsyn A, Ebel GD, Olson KE, Barbacioru C, et al. Small RNA profiling of dengue virus-mosquito interactions implicates the PIWI RNA pathway in anti-viral defense. BMC Microbiol. 2011;11:45

77. Myles KM, Wiley MR, Morazzani EM, Adelman ZN. Alphavirus-derived small RNAs modulate pathogenesis in disease vector mosquitoes. Proc Natl Acad Sci U S A. 2008;105:19938-43.
78. Welsch S, Miller S, Romero-Brey I, Merz A, Bleck CKE, Walther P, et al. Composition and three-dimensional architecture of the dengue virus replication and assembly sites. Cell Host Microbe. 2009;5:365-75.

79. Morazzani EM, Wiley MR, Murreddu MG, Adelman ZN, Myles KM. Production of virus-derived ping-pong-dependent piRNA-like small RNAs in the mosquito soma. PLoS Pathog. 2012;8:e1002470.

80. Schnettler E, Donald CL, Human S, Watson M, Siu RWC, McFarlane M, et al. Knockdown of piRNA pathway proteins results in enhanced Semliki Forest virus production in mosquito cells. J Gen Virol. 2013;94:1680-9.

81. Bennett KE, Olson KE, Munoz Mde L, Fernandez-Salas I, Farfan-Ale J, Higgs S, et al. Variation in vector competence for dengue 2 virus among 24 collections of Aedes aegypti from Mexico and the United States. Am J Trop Med Hyg. 2002;67:85-92.

82. Lozano-Fuentes S, Fernández-Salas I, de Lourdes MM, Garcia-Rejon J, Olson $K E$, Beaty BJ, et al. The neovolcanic axis is a barrier to gene flow among Aedes aegypti populations in Mexico that differ in vector competence for dengue 2 virus. PLoS Negl Trop Dis. 2009;3:e468.

83. Sylla M, Bosio C, Urdaneta-Marquez L, Ndiaye M, Black WC. Gene flow, subspecies composition, and dengue virus-2 susceptibility among Aedes aegypti collections in Senegal. PLoS Negl Trop Dis. 2009;3:e408.

84. Sim S, Jupatanakul N, Ramirez JL, Kang S, Romero-Vivas CM, Mohammed H, et al. Transcriptomic profiling of diverse Aedes aegypti strains reveals increased basal-level immune activation in dengue virus-refractory populations and identifies novel virus-vector molecular Interactions. PLoS Negl Trop Dis. 2013;7:e2295.

85. Black 4th WC, Bennett KE, Gorrochótegui-Escalante N, Barillas-Mury CV, Fernández-Salas I, de Lourdes MM, et al. Flavivirus susceptibility in Aedes aegypti. Arch Med Res. 2001;33:379-88.

86. Bosio C, Beaty B, Black 4th WC. Quantitative genetics of vector competence for dengue-2 virus in Aedes aegypti. Am J Trop Med Hyg. 1998;59:965-70.

87. Bosio CF, Fulton RE, Salasek ML, Beaty BJ, Black 4th WC. Quantitative trait loci that control vector competence for dengue-2 virus in the mosquito Aedes aegypti. Genetics. 2000;156:687-98.

88. Gomez-Machorro C, Bennett KE, del Lourdes MM, Black WC. Quantitative trait loci affecting dengue midgut infection barriers in an advanced intercross line of Aedes aegypti. Insect Mol Biol. 2004;13:637-48.

89. Bennett KE, Flick D, Fleming KH, Jochim R, Beaty BJ, Black 4th WC Quantitative trait loci that control dengue-2 virus dissemination in the mosquito Aedes aegypti. Genetics. 2005;170:185-94.

90. Lambrechts L, Chevillon C, Albright R, Thaisomboonsuk B, Richardson J, Jarman R, et al. Genetic specificity and potential for local adaptation between dengue viruses and mosquito vectors. BMC Evol Biol. 2009;9:160.

91. Fansiri T, Fontaine A, Diancourt L, Caro V, Thaisomboonsuk B, Richardson JH, et al. Genetic mapping of specific interactions between Aedes aegypti mosquitoes and dengue viruses. PLoS Genet. 2013;9:e1003621.

92. Lambrechts L. Quantitative genetics of Aedes aegypti vector competence for dengue viruses: towards a new paradigm? Trends Parasitol. 2011;27:111-4.

93. Lambrechts L, Quillery E, Noel V, Richardson JH, Jarman RG, Scott TW, et al. Specificity of resistance to dengue virus isolates is associated with genotypes of the mosquito antiviral gene Dicer-2. Proc R Soc B Biol Sci. 2012;280:20122437.

94. Nene V, Wortman JR, Lawson D, Haas B, Kodira C, Tu Z (Jake), et al. Genome sequence of Aedes aegypti, a major arbovirus vector. Science. 2007;316:1718-23.

95. Evans BR, Gloria-Soria A, Hou L, McBride C, Bonizzoni M, Zhao H, et al. A multipurpose high throughput SNP chip for the dengue and yellow fever mosquito, Aedes aegypti. G3 (Bethesda). 2015;5:711-8.

96. Faucon F, Dusfour I, Gaude T, Navratil V, Boyer F, Chandre F, et al. Identifying genomic changes associated with insecticide resistance in the dengue mosquito Aedes aegypti by deep targeted sequencing. Genome Res. 2015:25:1347-59.

97. Behura SK, Gomez-Machorro C, Harker BW, deBruyn B, Lovin DD, Hemme RR, et al. Global cross-talk of genes of the mosquito Aedes aegypti in response to dengue virus infection. PLoS Negl Trop Dis. 2011;5:e1385.

98. Behura SK, Gomez-Machorro C, deBruyn B, Lovin DD, Harker BW, Romero-Severson J, et al. Influence of mosquito genotype on transcriptional response to dengue virus infection. Funct Integr Genomics. 2014;14:581-9.

99. Chauhan C, Behura SK, deBruyn B, Lovin DD, Harker BW, Gomez-Machorro C, et al. Comparative expression profiles of midgut genes in dengue virus refractory and susceptible Aedes aegypti across critical period for virus infection. PLoS One. 2012;7:e47350. 
100. Bonizzoni M, Dunn WA, Campbell CL, Olson KE, Marinotti O, James AA. Strain variation in the transcriptome of the dengue fever vector, Aedes aegypti. G3 (Bethesda). 2012;2:103-14.

101. Dong Y, Manfredini F, Dimopoulos G. Implication of the mosquito midgut microbiota in the defense against malaria parasites. PLoS Pathog. 2009;5:e1000423.

102. Ramirez JL, Souza-Neto J, Torres Cosme R, Rovira J, Ortiz A, Pascale JM, et al. Reciprocal tripartite interactions between the Aedes aegypti midgut microbiota, innate immune system and dengue virus influences vector competence. PLoS Negl Trop Dis. 2012;6:e1561.

103. Minard G, Mavingui P, Moro CV. Diversity and function of bacterial microbiota in the mosquito holobiont. Parasit Vectors. 2013;6:146.

104. Dillon RJ, Dillon VM. The gut bacteria of insects: nonpathogenic interactions. Annu Rev Entomol. 2004:49:71-92.

105. Jupatanakul N, Sim S, Dimopoulos G. The insect microbiome modulates vector competence for Arboviruses. Viruses. 2014;6:4294-313.

106. Ramirez JL, Short SM, Bahia AC, Saraiva RG, Dong Y, Kang S, et al. Chromobacterium Csp_P reduces malaria and dengue infection in vector mosquitoes and has entomopathogenic and in vitro anti-pathogen activities. PLoS Pathog. 2014;10:e1004398.

107. Xi Z, Khoo CC, Dobson SL. Wolbachia establishment and invasion in an Aedes aegypti laboratory population. Science. 2005;310:326-8.

108. Mcmeniman CJ, Lane RV, Cass BN, Fong AW, Sidhu M, Wang Y-F, et al. Stable introduction of a life-shortening Wolbachia infection into the mosquito Aedes aegypti. Science. 2009;323:141-4.

109. Moreira LA, Iturbe-Ormaetxe I, Jeffery JA, Lu G, Pyke AT, Hedges LM, et al. A Wolbachia symbiont in Aedes aegypti limits infection with dengue, chikungunya, and Plasmodium. Cell. 2009;139:1268-78.

110. Bian $G, X u Y, L u P, X i e ~ Y, X i Z$. The endosymbiotic bacterium Wolbachia induces resistance to dengue virus in Aedes aegypti. PLoS Pathog. 2010;6:e1000833.

111. Walker T, Johnson PH, Moreira LA, Iturbe-Ormaetxe I, Frentiu FD, McMeniman CJ, et al. The wMel Wolbachia strain blocks dengue and invades caged Aedes aegypti populations. Nature. 2011:476:450-3.

112. Kambris Z, Cook PE, Phuc HK, Sinkins SP. Immune activation by life-shortening Wolbachia and reduced filarial competence in mosquitoes. Science. 2009;326:134-6.

113. Rancès $\mathrm{E}$, Ye YH, Woolfit M, McGraw EA, O'Neill SL. The relative importance of innate immune priming in Wolbachia-mediated dengue interference. PLoS Pathog. 2012;8:e1002548.

114. Molloy JC, Sinkins SP. Wolbachia do not induce reactive oxygen species-dependent immune pathway activation in Aedes albopictus. Viruses. 2015;7:4624-39

115. Caragata EP, Rancès E, Hedges LM, Gofton AW, Johnson KN, O'Neill SL, et al. Dietary cholesterol modulates pathogen blocking by Wolbachia. PLoS Pathog. 2013;9:e1003459.

116. Hussain M, Frentiu FD, Moreira LA, O'Neill SL, Asgari S. Wolbachia uses host microRNAs to manipulate host gene expression and facilitate colonization of the dengue vector Aedes aegypti. Proc Natl Acad Sci U S A. 2011;108:9250-5.

117. Zhang G, Hussain M, O'Neill SL, Asgari S. Wolbachia uses a host microRNA to regulate transcripts of a methyltransferase, contributing to dengue virus inhibition in Aedes aegypti. Proc Natl Acad Sci U S A. 2013;110:10276-81.

118. Sinkins SP. Wolbachia and cytoplasmic incompatibility in mosquitoes. Insect Biochem Mol Biol. 2004;34:723-9.

119. Wang Y, Gilbreath TM, Kukutla P, Yan G, Xu J. Dynamic gut microbiome across life history of the malaria mosquito Anopheles gambiae in Kenya. PLoS One. 2011;6:e24767.

120. Osei-Poku J, Mbogo CM, Palmer WJ, Jiggins FM. Deep sequencing reveals extensive variation in the gut microbiota of wild mosquitoes from Kenya. Mol Ecol. 2012;21:5138-50

121. Minard G, Tran F-H, Dubost A, Tran-Van V, Mavingui P, Valiente MC. Pyrosequencing $16 \mathrm{~S}$ rRNA genes of bacteria associated with wild tiger mosquito Aedes albopictus: a pilot study. Front Cell Infect Microbiol. 2014:4:59.

122. Boissière A, Tchioffo MT, Bachar D, Abate L, Marie A, Nsango SE, et al. Midgut microbiota of the malaria mosquito vector Anopheles gambiae and interactions with Plasmodium falciparum infection. PLoS Pathog. 2012;8:e1002742.

123. Moll RM, Romoser WS, Modrzakowski MC, Moncayo AC, Lerdthusnee K. Meconial peritrophic membranes and the fate of midgut bacteria during mosquito (Diptera: Culicidae) metamorphosis. J Med Entomol. 2001;38:29-32.
124. Hughes GL, Dodson BL, Johnson RM, Murdock CC, Tsujimoto H, Suzuki Y, et al. Native microbiome impedes vertical transmission of Wolbachia in Anopheles mosquitoes. Proc Natl Acad Sci U S A. 2014;111:12498-503.

125. Rossi P, Ricci I, Cappelli A, Damiani C, Ulissi U, Mancini MV, et al. Mutual exclusion of Asaia and Wolbachia in the reproductive organs of mosquito vectors. Parasit Vectors. 2015:8:278.

126. Ong SH, Kukkillaya VU, Wilm A, Lay C, Ho EXP, Low L, et al. Species identification and profiling of complex microbial communities using shotgun Illumina sequencing of $16 \mathrm{~S}$ rRNA amplicon sequences. PLoS One. 2013;8:e60811.

127. Chandler JA, Liu RM, Bennett SN. RNA shotgun metagenomic sequencing of northern California (USA) mosquitoes uncovers viruses, bacteria, and fungi. Front Microbiol. 2015;6:185.

128. Qin J, Li R, Raes J, Arumugam M, Burgdorf KS, Manichanh C, et al. A human gut microbial gene catalogue established by metagenomic sequencing. Nature. 2010;464:59-65.

129. Sridharan A, Chen Q, Tang KF, Ooi EE, Hibberd ML, Chen J. Inhibition of megakaryocyte development in the bone marrow underlies dengue virusinduced thrombocytopenia in humanized mice. J Virol. 2013;87:11648-58.

130. Jessie K, Fong MY, Devi S, Lam SK, Wong KT. Localization of dengue virus in naturally infected human tissues, by immunohistochemistry and in situ hybridization. J Infect Dis. 2004;189:1411-8.

131. Durbin A, Vargas M, Wanionek K, Hammond S, Gordon A, Rocha C, et al. Phenotyping of peripheral blood mononuclear cells during acute dengue illness demonstrates infection and increased activation of monocytes in severe cases compared to classic dengue fever. Virology. 2008;376:429-35.

132. Simmons CP, Farrar JJ, van Vinh CN, Wills B. Dengue. N Engl J Med. 2012:366:1423-32.

133. van de Weg CAM, van den Ham H-J, Bijl MA, Anfasa F, Zaaraoui-Boutahar F, Dewi $\mathrm{BE}$, et al. Time since onset of disease and individual clinical markers associate with transcriptional changes in uncomplicated dengue. PLoS Negl Trop Dis. 2015;9:e0003522.

134. Sun P, García J, Comach G, Vahey MT, Wang Z, Forshey BM, et al. Sequential waves of gene expression in patients with clinically defined dengue illnesses reveal subtle disease phases and predict disease severity. PLoS Negl Trop Dis. 2013;7:e2298.

135. Long HT, Hibberd ML, Hien TT, Dung NM, Van Ngoc T, Farrar J, et al. Patterns of gene transcript abundance in the blood of children with severe or uncomplicated dengue highlight differences in disease evolution and host response to dengue virus infection. J Infect Dis. 2009;199:537-46.

136. Hoang LT, Lynn DJ, Henn M, Birren BW, Lennon NJ, Le PT, et al. The early whole-blood transcriptional signature of dengue virus and features associated with progression to dengue shock syndrome in Vietnamese children and young adults. J Virol. 2010;84:12982-94.

137. Fink J, Gu F, Ling L, Tolfvenstam T, Olfat F, Chin KC, et al. Host gene expression profiling of dengue virus infection in cell lines and patients. PLoS Negl Trop Dis. 2007;1:e86.

138. Ubol S, Masrinoul P, Chaijaruwanich J, Kalayanarooj S, Charoensirisuthikul T, Kasisith J. Differences in global gene expression in peripheral blood mononuclear cells indicate a significant role of the innate responses in progression of dengue fever but not dengue hemorrhagic fever. J Infect Dis. 2008:197:1459-67.

139. Simmons CP, Popper S, Dolocek C, Chau TNB, Griffiths M, Dung NTP, et al. Patterns of host genome-wide gene transcript abundance in the peripheral blood of patients with acute dengue hemorrhagic fever. J Infect Dis. 2007:195:1097-107.

140. Tolfvenstam T, Lindblom A, Schreiber MJ, Ling L, Chow A, Ooi EE, et al. Characterization of early host responses in adults with dengue disease. BMC Infect Dis. 2011;11:209.

141. Bidet K, Dadlani D, Garcia-Blanco MA. G3BP1, G3BP2 and CAPRIN1 are required for translation of interferon stimulated mRNAs and are targeted by a dengue virus non-coding RNA. PLoS Pathog. 2014;10:e1004242.

142. Low JG, Sung C, Wijaya L, Wei Y, Rathore APS, Watanabe S, et al. Efficacy and safety of celgosivir in patients with dengue fever (CELADEN): a phase $1 \mathrm{~b}$, randomised, double-blind, placebo-controlled, proof-of-concept trial. Lancet Infect Dis. 2014;14:706-15.

143. Nascimento EJM, Braga-Neto U, Calzavara-Silva CE, Gomes ALV, Abath FGC, Brito CAA, et al. Gene expression profiling during early acute febrile stage of dengue Infection can predict the disease outcome. PLoS One. 2009;4:e7892.

144. Popper SJ, Gordon A, Liu M, Balmaseda A, Harris E, Relman DA. Temporal dynamics of the transcriptional response to denque virus infection in Nicaraguan children. PLoS Negl Trop Dis. 2012;6:e1966. 
145. Devignot S, Sapet C, Duong V, Bergon A, Rihet P, Ong S, et al. Genomewide expression profiling deciphers host responses altered during dengue shock syndrome and reveals the role of innate immunity in severe dengue. PLoS One. 2010;5:e11671.

146. Loke P'n, Hammond SN, Leung JM, Kim CC, Batra S, Rocha C, et al. Gene expression patterns of denque virus-infected children from Nicaragua reveal a distinct signature of increased metabolism. PLoS Negl Trop Dis. 2010;4:e710.

147. Hermant B, Bibert S, Concord E, Dublet B, Weidenhaupt M, Vernet T, et al. Identification of proteases involved in the proteolysis of vascular endothelium Cadherin during neutrophil transmigration. J Biol Chem. 2003;278:14002-12.

148. World Health Organization. Dengue guidelines for diagnosis, treatment, prevention and control: new edition. 2009. http://www.who.int/rpc/ guidelines/9789241547871/en/. Accessed 3 Dec 2015.

149. Brasier AR, Zhao Y, Wiktorowicz JE, Spratt HM, Nascimento EJM, Cordeiro MT, et al. Molecular classification of outcomes from dengue virus-3 infections. J Clin Virol. 2015;64:97-106.

150. Brasier AR, Garcia J, Wiktorowicz JE, Spratt HM, Comach G, Ju H, et al. Discovery proteomics and nonparametric modeling pipeline in the development of a candidate biomarker panel for dengue hemorrhagic fever. Clin Transl Sci. 2012;5:8-20.

151. van de Weg CAM, Pannuti CS, de Araújo ESA, van den Ham H-J, Andeweg AC, Boas LSV, et al. Microbial translocation is associated with extensive immune activation in dengue virus infected patients with severe disease. PLoS Negl Trop Dis. 2013;7:e2236.

152. Kumar V, Kato N, Urabe Y, Takahashi A, Muroyama R, Hosono N, et al. Genome-wide association study identifies a susceptibility locus for HCV-induced hepatocellular carcinoma. Nat Genet. 2011;43:455-8.

153. Khor CC, Bich CTN, Pang J, Davila S, Long HT, Ong RTH, et al. Genome-wide association study identifies susceptibility loci for Dengue shock syndrome at MICB and PLCE1. Nat Genet. 2011:43:1139-41.

154. González S, López-Soto A, Suarez-Alvarez B, López-Vázquez A, López-Larrea C. NKG2D ligands: key targets of the immune response. Trends Immunol. 2008;29:397-403.

155. Libraty DH, Endy TP, Houng H-SH, Green S, Kalayanarooj S, Suntayakorn S, et al. Differing influences of virus burden and immune activation on disease severity in secondary dengue-3 virus infections. J Infect Dis. 2002;185:1213-21.

156. Vaughn DW, Green S, Kalayanarooj S, Innis BL, Nimmannitya S, Suntayakorn $S$, et al. Dengue viremia titer, antibody response pattern, and virus serotype correlate with disease severity. J Infect Dis. 2000;181:2-9.

157. Hinkes B, Wiggins RC, Gbadegesin R, Vlangos CN, Seelow D, Nürnberg G, et al. Positional cloning uncovers mutations in PLCE1 responsible for a nephrotic syndrome variant that may be reversible. Nat Genet. 2006;38:1397-405.

158. Sadowski CE, Lovric S, Ashraf S, Pabst WL, Gee HY, Kohl S, et al. A single-gene cause in $29.5 \%$ of cases of steroid-resistant nephrotic syndrome. J Am Soc Nephrol. 2015;26:1279-89.

159. Vasanwala FF, Thein T-L, Leo Y-S, Gan VC, Hao Y, Lee LK, et al. Predictive value of proteinuria in adult dengue severity. PLoS Negl Trop Dis. 2014;8:e2712.

160. Newton-Cheh C, Johnson T, Gateva V, Tobin MD, Bochud M, Coin L, et al. Genome-wide association study identifies eight loci associated with blood pressure. Nat Genet. 2009:41:666-76.

161. Gamble J, Bethell D, Day NPJ, Loc PP, Phu NH, Gartside IB, et al. Age-related changes in microvascular permeability: a significant factor in the susceptibility of children to shock? Clin Sci. 2000;98:211-6.

162. Barniol J, Gaczkowski R, Barbato EV, da Cunha RV, Salgado D, Martínez E, et al. Usefulness and applicability of the revised dengue case classification by disease: multi-centre study in 18 countries. BMC Infect Dis. 2011;11:106.

163. Narvaez F, Gutierrez G, Pérez MA, Elizondo D, Nuñez A, Balmaseda A, et al. Evaluation of the traditional and revised $\mathrm{WHO}$ classifications of dengue disease severity. PLoS Negl Trop Dis. 2011;5:e1397.

164. Leo Y-S, Gan VC, Ng E-L, Hao Y, Ng L-C, Pok K-Y, et al. Utility of warning signs in guiding admission and predicting severe disease in adult dengue. BMC Infect Dis. 2013;13:498.

165. Alexander N, Balmaseda A, Coelho ICB, Dimaano E, Hien TT, Hung NT, et al. Multicentre prospective study on dengue classification in four South-east Asian and three Latin American countries. Trop Med Int Health. $2011 ; 16: 936-48$
166. Pang J, Lindblom A, Tolfvenstam T, Thein T-L, Naim ANM, Ling L, et al. Discovery and validation of prognostic biomarker models to guide triage among adult dengue patients at early infection. PLOS ONE. 2016; in press.

167. Tanner L, Schreiber M, Low JG, Ong A, Tolfvenstam T, Lai YL, et al. Decision tree algorithms predict the diagnosis and outcome of dengue fever in the early phase of illness. PLoS Negl Trop Dis. 2008;2:e196.

168. Nguyen NM, Tran CNB, Phung LK, Duong KTH, Huynh H I A, Farrar J, et al. A randomized, double-blind placebo controlled trial of Balapiravir, a polymerase inhibitor, in adult dengue patients. J Infect Dis. 2013;207:1442-50.

169. Tam DTH, Ngoc TV, Tien NTH, Kieu NTT, Thuy TTT, Thanh LTC, et al. Effects of short-course oral corticosteroid therapy in early dengue infection in Vietnamese patients: a randomized, placebo-controlled trial. Clin Infect Dis. 2012;55:1216-24.

170. Whitehorn J, Nguyen CW, Khanh LP, Kien DTH, Quyen NTH, Tran NTT, et al. Lovastatin for the treatment of adult patients with dengue: a randomized, double-blind, placebo-controlled trial. Clin Infect Dis. 2015;civ949.

171. Nguyen THT, Nguyen $T H Q$, Vu TT, Farrar J, Hoang TL, Dong THT, et al. Corticosteroids for dengue - why don't they work? PLoS Negl Trop Dis. 2013;7:e2592.

172. Durbin AP, Whitehead SS. Next-generation dengue vaccines: novel strategies currently under development. Viruses. 2011;3:1800-14.

173. Lim SP, Wang Q-Y, Noble CG, Chen Y-L, Dong H, Zou B, et al. Ten years of dengue drug discovery: progress and prospects. Antiviral Res. 2013;100:500-19.

174. Seib KL, Dougan G, Rappuoli R. The key role of genomics in modern vaccine and drug design for emerging infectious diseases. PLoS Genet. 2009:5:e1000612.

175. Züst R, Dong H, Li X-F, Chang DC, Zhang B, Balakrishnan T, et al. Rational design of a live attenuated dengue vaccine: 2'-O-methyltransferase mutants are highly attenuated and immunogenic in mice and macaques. PLoS Pathog. 2013;9:e1003521.

176. Klumpp K, Lévêque $V$, Pogam SL, Ma H, Jiang W-R, Kang $H$, et al. The novel nucleoside analog R1479 (4'-azidocytidine) is a potent inhibitor of NS5B-dependent RNA synthesis and hepatitis C virus replication in cell culture. J Biol Chem. 2006;281:3793-9.

177. Perry ST, Buck MD, Plummer EM, Penmasta RA, Batra H, Stavale EJ, et al. An iminosugar with potent inhibition of dengue virus infection in vivo. Antiviral Res. 2013;98:35-43.

178. Hoffmann AA, Montgomery BL, Popovici J, Iturbe-Ormaetxe I, Johnson PH, Muzzi F, et al. Successful establishment of Wolbachia in Aedes populations to suppress dengue transmission. Nature. 2011;476:454-7.

179. Eliminate Dengue Program. Eliminate dengue: our challenge. http://www. eliminatedengue.com/program. Accessed 13 Aug 2015.

180. Fu G, Lees RS, Nimmo D, Aw D, Jin L, Gray P, et al. Female-specific flightless phenotype for mosquito control. Proc Natl Acad Sci U S A. 2010;107:4550-4

181. Phuc HK, Andreasen MH, Burton RS, Vass C, Epton MJ, Pape G, et al. Late-acting dominant lethal genetic systems and mosquito control. BMC Biol. 2007;5:11.

182. Lacroix R, McKemey AR, Raduan N, Kwee Wee L, Hong Ming W, Guat Ney T, et al. Open field release of genetically engineered sterile male Aedes aegypti in Malaysia. PLoS One. 2012;7:e42771.

183. Harris AF, Nimmo D, McKemey AR, Kelly N, Scaife S, Donnelly CA, et al. Field performance of engineered male mosquitoes. Nat Biotechnol. 2011:29:1034-7

184. Harris AF, McKemey AR, Nimmo D, Curtis Z, Black I, Morgan SA, et al. Successful suppression of a field mosquito population by sustained release of engineered male mosquitoes. Nat Biotechnol. 2012;30:828-30.

185. Carvalho DO, McKemey AR, Garziera L, Lacroix R, Donnelly CA, Alphey L, et al. Suppression of a field population of Aedes aegypti in Brazil by sustained release of transgenic male mosquitoes. PLoS Negl Trop Dis. 2015;9:e0003864.

186. Jupatanakul N, Sim S, Dimopoulos G. Aedes aegypti ML and Niemann-Pick type C family members are agonists of dengue virus infection. Dev Comp Immunol. 2014:43:1-9.

187. Xiao X, Liu Y, Zhang X, Wang J, Li Z, Pang X, et al. Complement-related proteins control the Flavivirus infection of Aedes aegypti by inducing antimicrobial peptides. PLoS Pathog. 2014;10:e1004027.

188. Choy MM, Sessions OM, Gubler DJ, Ooi EE. Production of infectious dengue virus in Aedes aegypti is dependent on the ubiquitin proteasome pathway. PLoS Negl Trop Dis. 2015;9:e0004227. 
189. Kang S, Shields AR, Jupatanakul N, Dimopoulos G. Suppressing dengue-2 infection by chemical inhibition of Aedes aegypti host factors. PLoS Negl Trop Dis. 2014;8:e3084.

190. Bian G, Shin SW, Cheon HM, Kokoza V, Raikhel AS. Transgenic alteration of Toll immune pathway in the female mosquito Aedes aegypti. Proc Natl Acad Sci U S A. 2005;102:13568-73.

191. Antonova Y, Alvarez KS, Kim YJ, Kokoza V, Raikhel AS. The role of NF-kappaB factor REL2 in the Aedes aegypti immune response. Insect Biochem Mol Biol. 2009:39:303-14

192. Franz AWE, Sánchez-Vargas I, Adelman ZN, Blair CD, Beaty BJ, James AA, et al. Engineering RNA interference-based resistance to dengue virus type 2 in genetically modified Aedes aegypti. Proc Natl Acad Sci U S A. 2006;103:4198-203.

193. Riehle M, Moreira C, Lampe D, Lauzon C, Jacobslorena M. Using bacteria to express and display anti-Plasmodium molecules in the mosquito midgut. Int J Parasitol. 2007;37:595-603.

194. Bisi DC, Lampe DJ. Secretion of anti-Plasmodium effector proteins from a natural Pantoea agglomerans isolate by using PelB and HlyA secretion signals. Appl Env Microbiol. 2011;77:4669-75.

195. Fang W, Vega-Rodríguez J, Ghosh AK, Jacobs-Lorena M, Kang A, St. Leger RJ. Development of transgenic fungi that kill human malaria parasites in mosquitoes. Science. 2011;331:1074-7.

196. Hammond A, Galizi R, Kyrou K, Simoni A, Siniscalchi C, Katsanos D, et al. A CRISPR-Cas9 gene drive system targeting female reproduction in the malaria mosquito vector Anopheles gambiae. Nat Biotechnol. 2015;34:78-83.

197. Gantz VM, Jasinskiene N, Tatarenkova O, Fazekas A, Macias VM, Bier E, et al. Highly efficient Cas9-mediated gene drive for population modification of the malaria vector mosquito Anopheles stephensi. Proc Natl Acad Sci U S A. 2015;112:E6736-43.

198. Esvelt KM, Smidler AL, Catteruccia F, Church GM. Concerning RNA-guided gene drives for the alteration of wild populations. eLife. 2014;3:e03401.

199. World Health Organization. 2014. http://gamapserver.who.int/mapLibrary/ Files/Maps/Global_DengueTransmission_ITHRiskMap.png?ua=1. Accessed 4 Feb 2016. 